\title{
Avaliação da hidrofobicidade e da formação de biofilme em poliestireno por Salmonella Heidelberg isoladas de abatedouro avícola
}

\author{
Hydrophobicity and biofilm formation on polystyrene \\ by Salmonella Heidelberg isolated from a poultry slaughterhouse \\ Laura Beatriz Rodrigues, ${ }^{1,2}$ Luciana Ruschel dos Santos', Natalie Nadin Rizzo', \\ Vinícius Zancanaro Tagliari', Amauri Picollo de Oliveira', Graciela Trenhago', Sílvio Cezar Rodegheri', \\ Ricardo Manoel Taglieti', Elci Lotar Dickel' \& Vladimir Pinheiro do Nascimento ${ }^{2,3}$

\section{RESUMO}

Bactérias do gênero Salmonella são consideradas a principal causa de infecções alimentares em humanos associadas a produtos avícolas, na maioria dos países. São capazes de formar biofilmes em diferentes superfícies, dificultando sua eliminação por procedimentos de limpeza e sanificação na indústria de alimentos. Estudos demonstram uma melhor adesão microbiana com o aumento da hidrofobicidade, tanto da superfície celular como do substrato de adesão. Neste trabalho, avaliou-se a formação de biofilme em placas de poliestireno por $S$. Heidelberg isoladas de abatedouros avícolas, cultivadas em caldo TSB com diferentes concentrações de glicose e a hidrofobicidade destas cepas na fase logarítmica (4h) e na fase estacionária (24h) do crescimento bacteriano. No caldo TSB sem suplementação de glicose, todas as amostras foram capazes de formar biofilme, sendo duas amostras fortemente formadoras de biofilme, e a maioria fracamente formadora. Nos caldos TSB com 0,5, 1,0 e 1,5\% de glicose, todas as amostras foram fracamente formadoras. Nos caldos TSB com 2,0 a 4,0\% de glicose, várias amostras apresentaram-se não formadoras e as demais fracamente formadoras. Após a incubação a $36^{\circ} \mathrm{C}$ por 4 horas, $\mathrm{o}$ índice de hidrofobicidade foi inferior a $10 \%$, com todas as amostras sendo altamente hidrofílicas. Na incubação a $36^{\circ} \mathrm{C}$ por 24 horas, os resultados foram distintos, sendo 1/16 altamente hidrofóbica, 9/16 com média hidrofobicidade e 6/16 altamente hidrofílicas. As $S$. Heidelberg foram capazes de formar biofilmes no poliestireno, enfatizando a necessidade da sua verificação em outras superfícies, além de avaliar outros hidrocarbonetos e tempos de incubação relacionados aos índices de hidrofobicidade.

Descritores: Salmonella, biofilme, hidrofobicidade, poliestireno.

\section{ABSTRACT}

Bacteria of the genus Salmonella are regarded as the major cause of food poisoning in humans, being associated with the consumption of poultry products in most countries. These bacteria can produce biofilm on different surfaces, and consequently, cleaning and sanitation procedures used in the food industry cannot remove them easily. Studies have shown that bacterial adhesion improves as hydrophobicity (both of the cell surface and of the adhesion substrate) increases. The present study assessed biofilm formation on polystyrene plates by $S$. Heidelberg strains isolated from poultry slaughterhouses, grown on TSB at different glucose concentrations, and the hydrophobicity of these strains in the logarithmic phase (4h) and in the stationary phase (24h) of bacterial growth. In TSB without glucose supplementation, all strains produced biofilm; two of them were strong biofilm producers, and most of them were weak biofilm producers. In TSB with $0.5,1.0$ and $1.5 \%$ dof glucose, all strains were weak biofilm producers. In TSB with 2.0 to $4.0 \%$ of glucose, several strains did not produce biofilm, whereas others were weak biofilm producers. After incubation at $36^{\circ} \mathrm{C}$ for $4 \mathrm{~h}$, the hydrophobicity index was less than $10 \%$, and all strains were highly hydrophilic. Incubation at $36^{\circ} \mathrm{C}$ for $24 \mathrm{~h}$ yielded different results: 1 out of 16 strains was highly hydrophobic, 9 out of 16 were moderately hydrophobic and 6 out of 16 were highly hydrophilic. S. Heidelberg strains formed biofilm on polystyrene, which underscores the necessity to verify biofilm formation on other surfaces, in addition to investigating other hydrocarbons and incubation times in relation to hydrophobicity indices.

Keywords: Salmonella, biofilm, hydrophobicity, polystyrene.

${ }^{1}$ Faculdade de Agronomia e Medicina Veterinária, Universidade de Passo Fundo (UPF), BR 285, Km 171, Bairro São José, CEP $99052-900$ Passo Fundo, RS, Brasil. ${ }^{2}$ Programa de Pós-graduação em Ciências Veterinárias (PPGCV), Universidade Federal do Rio Grande do Sul (UFRGS), Porto Alegre, RS. ${ }^{3}$ Departamento de Medicina Animal, Faculdade de Veterinária, UFRGS. CORRESPONDÊNCIA: L.B. Rodrigues [laurab@upf.br ; Fax: + 55 (54) 3316 8163]. 


\section{INTRODUÇÃO}

Dentre os contaminantes da carne de aves, a Salmonella spp. é o mais relevante enteropatógeno humano em surtos associados ao consumo deste alimento. São capazes de formar biofilme em diferentes superfícies. Na indústria alimentícia, muitas vezes, encontram ambientes propícios para seu desenvolvimento, aumentando o risco da contaminação devido à sua permanência após a higienização $[4,16]$.

Os biofilmes em condições naturais tendem a ser compostos por micro-organismos em culturas mistas, e são considerados mais resistentes aos produtos utilizados comumente para limpeza e sanificação $[8,10]$. A formação e presença de biofilme têm sido estudadas através do uso de diferentes metodologias de quantificação, sendo muito utilizado o ensaio em placas de microtitulação [2].

As propriedades físico-químicas da superfície podem exercer uma forte influência sobre a adesão dos micro-organismos, os quais aderem mais facilmente às superfícies hidrofóbicas (plásticos) do que às hidrofílicas (vidro ou metais). Estudos mostram que a adesão microbiana se torna melhor com o aumento da hidrofobicidade, tanto da superfície celular como do substrato de adesão [7].

Assim, os objetivos deste trabalho são avaliar a formação de biofilme em placas de poliestireno por Salmonella Heidelberg ( $\mathrm{SH}$ ) isoladas de abatedouro avícola e cultivadas em caldo TSB com diferentes concentrações de glicose e avaliar a hidrofobicidade destas cepas em diferentes tempos de incubação: no início da fase logarítmica (4 horas) e na fase estacionária (24 horas).

\section{MATERIAS E MÉTODOS}

A metodologia foi baseada em técnicas descritas [17,18], adaptadas para a análise de 15 amostras de $S$. Heidelberg ( $\mathrm{SH}$ ) isoladas em abatedouro avícola de carcaças antes do chiller ou depois do chiller e de suabes de cloaca (Tabela 1), obtidas em experimento realizado anteriormente [6]. A cepa padrão utilizada foi a $S$. Typhimurium ATCC 14028.

As amostras foram inoculadas em ágar TSA ${ }^{1}$ (Tryptic Soy Broth without Dextrose, com 1,5\% de agar) sem glicose (0\%) e TSA suplementado com 0,$5 ; 1 ; 1,5$; $2 ; 2,5 ; 3 ; 3,5$ e $4 \%$ de glicose, incubadas a $36^{\circ} \mathrm{C}$ por 24

Tabela 1. Amostras de Salmonella Heidelberg utilizadas no trabalho, provenientes de abatedouro avícola, isoladas de carcaças antes do chiller, depois do chiller e de suabes de cloaca, e cepa padrão Salmonella Typhimurium ATCC 14028.

\begin{tabular}{lccc}
\hline Sigla & Micro-organismo & Momento da colheita & Tipo de amostra \\
\hline EB1 & S. Typhimurium ATCC 14028 & - & - \\
EB2 & Salmonella Heidelberg & Antes do chiller & Carcaça de frango \\
EB3 & Salmonella Heidelberg & Depois do chiller & Carcaça de frango \\
EB4 & Salmonella Heidelberg & Antes do chiller & Carcaça de frango \\
EB5 & Salmonella Heidelberg & Antes do chiller & Carcaça de frango \\
EB6 & Salmonella Heidelberg & Antes do chiller & Carcaça de frango \\
EB7 & Salmonella Heidelberg & Antes do chiller & Carcaça de frango \\
EB8 & Salmonella Heidelberg & Antes do chiller & Carcaça de frango \\
EB9 & Salmonella Heidelberg & Depois do chiller & Carcaça de frango \\
EB10 & Salmonella Heidelberg & Depois do chiller & Carcaça de frango \\
EB11 & Salmonella Heidelberg & Antes do chiller & Carcaça de frango \\
EB12 & Salmonella Heidelberg & Antes do chiller & Carcaça de frango \\
EB13 & Salmonella Heidelberg & Depois do chiller & Carcaça de frango \\
EB14 & Salmonella Heidelberg & Antes do chiller & Carcaça de frango \\
EB15 & Salmonella Heidelberg & Antes da depenadeira & Suabe de cloaca \\
EB16 & Salmonella Heidelberg & Antes da depenadeira & Suabe de cloaca \\
\hline
\end{tabular}


horas e transferidas para caldo TSB ${ }^{1}$ (Tryptic Soy Broth without Dextrose), com 0,5\% de cloreto de sódio em sua formulação, com as mesmas concentrações de glicose e incubação a $36^{\circ} \mathrm{C}$ por 24 horas. Em seguida, alíquotas das culturas foram adicionadas em caldo TSB com a mesma concentração de glicose até atingir a escala 1 de MacFarland.

Posteriormente, $200 \mu \mathrm{L}$ de cada suspensão bacteriana foram inoculados, em triplicata, em poços de placas estéreis de microtitulação de poliestireno de 96 cavidades com fundo plano $^{2}$. Os controles negativos foram poços com caldos TSB com cada concentração de glicose, em triplicata, não inoculados. As placas foram incubadas a $36^{\circ} \mathrm{C}$ por 24 horas. A suspensão bacteriana foi aspirada e cada poço foi lavado 3 vezes com $250 \mu \mathrm{L}$ de solução fisiológica a $0,9 \%$ estéril. Após, foi realizada a fixação do biofilme com $200 \mu \mathrm{L}$ de metanol p. $\mathrm{a}^{3}$ por 15 minutos, com posterior remoção. As placas foram secas à temperatura ambiente, coradas com $200 \mu \mathrm{L}$ de solução de cristal violeta ${ }^{3}$ de Hucker 2\% durante 5 minutos, lavadas em água corrente e secas à temperatura ambiente. Após foi realizada a leitura da absorbância em leitor de ELISA (Rosys Anthos 2010) a 550nm.

O valor da densidade óptica de cada amostra (Doa) foi obtido pela média aritmética da absorbância dos três poços e esse valor foi comparado com a média da absorbância dos controles negativos (Docn). Para determinar o grau de formação de biofilme, foi utilizada a seguinte classificação: não formadora de biofilme (Doa $\leq$ Docn), fracamente formadora de biofilme (Docn $\leq$ Doa $\leq 2$. Docn), moderadamente formadora de biofilme (2.Docn $<$ Doa $\leq 4$.Docn) e fortemente formadora de biofilme (4.Docn $<$ Doa).

Para avaliar a hidrofobicidade, foram analisadas as mesmas 15 amostras de $S$. Heidelberg (SH) isoladas em abatedouro avícola, e a cepa padrão $S$. Typhimurium ATCC 14028, em diferentes tempos de incubação. Inoculou-se as amostras em duplicatas do caldo $\mathrm{BHI}^{1}$ a $36^{\circ} \mathrm{C}$, mantendo-os na estufa por 4 horas e por 24 horas. Em ambos os tempos, padronizou-se $4 \mathrm{~mL}$ de uma suspensão bacteriana com tampão $\mathrm{PBS}(0,01 \mathrm{M}, \mathrm{Ph} 7,2)$ em DO igual a 1.0 através da leitura da absorbância por espectrofotometria a $400 \mathrm{~nm}$. Posteriormente, $3,6 \mathrm{~mL}$ de cada suspensão bacteriana foi adicionada a $0,4 \mathrm{~mL}$ de hidrocarboneto, neste caso, o xileno ${ }^{3}$. A mistura foi agitada em vortex por $5 \mathrm{~min}$ e deixada em repouso por 20min. Atingido o equilíbrio das fases oleosa/aquosa, a camada inferior foi removida e lida a absorbância a 400nm. Considerou-se como branco o caldo BHI não inoculado, com tampão PBS e xileno, agitado, deixado em repouso e com remoção da camada inferior. $\mathrm{O}$ índice de hidrofobicidade (IH) foi determinado aplicando-se a fórmula: $\mathrm{IH}=100 \times(\mathrm{Vi}-\mathrm{Vf}) / \mathrm{Vi}$, sendo $\mathrm{Vi}$ absorbância inicial e Vf absorbância final. Considerouse para $\mathrm{IH}>70 \%$ a bactéria altamente hidrofóbica, para $\mathrm{IH}<30 \%$ altamente hidrofílica e para $30 \%<\mathrm{IH}<70 \%$ média hidrofobicidade [9].

Tabela 2. Resultados da formação de biofilme nas placas de microtitulação de poliestireno para Salmonella Heidelberg em caldo TSB com diferentes concentrações de glicose, e cepa padrão Salmonella Typhimurium ATCC 14028.

\begin{tabular}{lcccc}
\hline Meios testados & $\begin{array}{c}\text { Não } \\
\text { formadores } \\
\text { de biofilme }\end{array}$ & $\begin{array}{c}\text { Fracamente } \\
\text { formadoras } \\
\text { de biofilme }\end{array}$ & $\begin{array}{c}\text { Moderadamente } \\
\text { formadoras } \\
\text { de biofilme }\end{array}$ & $\begin{array}{c}\text { Fortemente } \\
\text { formadoras } \\
\text { de biofilme }\end{array}$ \\
\hline TSB sem G & 0 & 14 & 0 & 2 \\
TSB + $0,5 \%$ G & 0 & 16 & 0 & 0 \\
TSB + $1 \%$ G & 0 & 16 & 0 & 0 \\
TSB $+1,5 \%$ G & 0 & 16 & 0 & 0 \\
TSB $+2 \%$ G & 6 & 10 & 0 & 0 \\
TSB $+2,5 \%$ G & 12 & 4 & 0 & 0 \\
TSB $+3 \% \mathrm{G}$ & 7 & 9 & 0 & 0 \\
TSB $+3,5 \% \mathrm{G}$ & 4 & 12 & 0 & 0 \\
TSB $+4 \% \mathrm{G}$ & 2 & 14 & 0 & 0 \\
\hline
\end{tabular}

TSB: Tryptic Soy Broth without Dextrose. G: Glucose. 


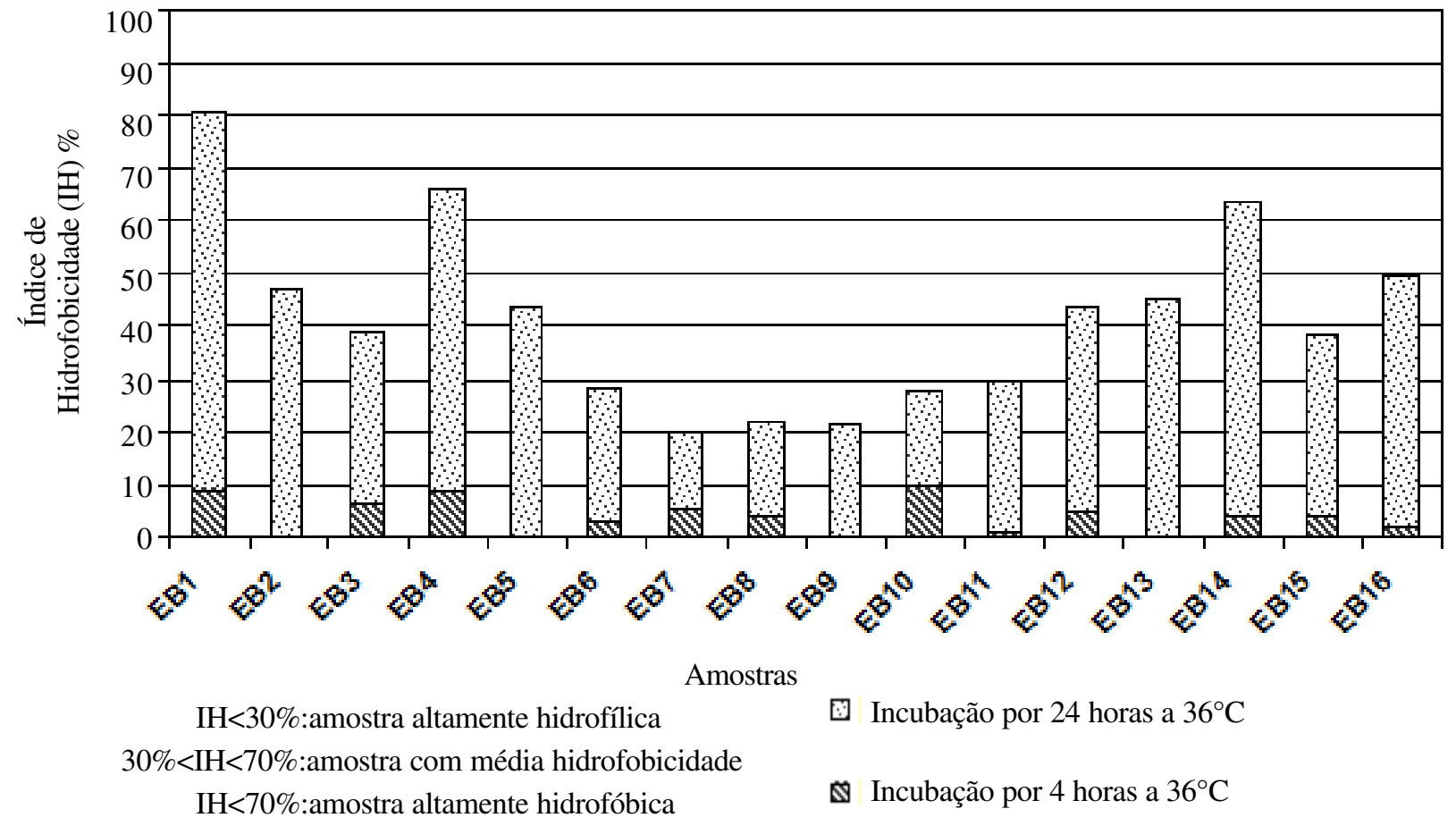

Figura 1. Resultados obtidos na avaliação da hidrofobicidade de Salmonella Heidelberg em caldo BHI em incubação por 4 e 24 horas, e cepa padrão Salmonella Typhimurium ATCC 14028.

\section{RESULTADOS}

$\mathrm{Na}$ incubação em caldo TSB sem suplementação de glicose, todas as amostras foram capazes de formar biofilme, sendo a maioria fracamente formadora de biofilme. Duas amostras no TSB com 0\% de glicose foram fortemente formadoras de biofilme, a EB7 e a EB10, ambas provenientes de carcaças, conforme demonstrado na Tabela 2. Nos caldos TSB com $0,5 \%$ de glicose, TSB com 1,0\% de glicose e TSB com $1,5 \%$ de glicose, todas as amostras foram fracamente formadoras. A partir da incubação nos caldos TSB suplementados com 2,0 a 4,0\% de glicose, várias amostras apresentaram-se não formadoras e as demais, fracamente formadoras. A amostra EB10 apresentou a capacidade de formar biofilme em todas as concentrações, e foi considerada fracamente formadora em todos os caldos suplementados com glicose.

Com relação à hidrofobicidade, de acordo com a Figura 1, observou-se que, após a incubação a $36^{\circ} \mathrm{C}$ por 4 horas, o índice de hidrofobicidade foi inferior a $10 \%$, considerando todas as amostras (16/16) altamente hidrofílicas. $\mathrm{Na}$ incubação a $36^{\circ} \mathrm{C}$ por 24 horas, as amostras apresentaram resultados distintos, sendo 1/16 altamente hidrofóbica (EB1), 9/16 com média hidrofobicidade (EB2 a EB5 e EB12 a EB16) e 6/16 altamente hidrofílicas (EB6 a EB11).

\section{DISCUSSÃO}

Um biofilme é uma comunidade de microorganismos sésseis caracterizada por células que se aderem a uma superfície, embebida em uma matriz extracelular formada por exopolissacarídeos, e exibe um fenótipo alterado quanto ao seu crescimento, expressão gênica e produção de proteínas [7]. Sua formação em indústrias alimentícias é de especial importância, por seu potencial como uma fonte crônica de contaminação microbiana aos alimentos, podendo transmitir doenças, além de aumentar a resistência à limpeza e sanitização [16].

A quantificação de biofilmes iniciaram com um método baseado no seu cultivo em tubos teste e subsequente coloração para detecção e reconhecimento do biofilme. Após, os poços das placas de microtitulação foram usados como recipiente para cultivo, e os resultados foram medidos por espectrofotometria. Diferentes métodos podem ser utilizados como os tubos teste, placas de microtitulação, microscopia, testes em placas de agar vermelho Congo, entre outros. No entanto, o método das placas de microtitulação permanece entre os ensaios mais frequentemente usados para investigação de biofilme [12,18].

Foi quantificada a formação de biofilme por 122 amostras de Salmonella spp. em superfície de 
poliestireno [16], utilizando infusão cérebro coração (BHI), caldo triptona de soja (TSB), caldo de carne (MB) e caldo triptona de soja diluído 1/20 (1/20-TSB) em placas de microtitulação. Os nutrientes contidos nos meios influenciaram significativamente a quantidade de biofilme produzido. O caldo TSB diluído (1/20-TSB) foi o mais efetivo em promover a produção de biofilme pelas amostras de Salmonella avaliadas, seguido pelo TSB. O caldo de carne e o BHI foram os menos efetivos. Deste modo, os pesquisadores concluíram que as Salmonella spp. testadas produziram mais biofilme em meios com nutrientes limitados.

Das $S$. Heidelberg testadas, todas foram provenientes de abatedouro avícola e formaram biofilme em meio sem adição de glicose, o que demonstra a capacidade de desenvolvimento biofilme em ambiente sem glicose, como já foi demonstrado anteriormente por estudos com Salmonella spp. e também com a $E$. coli O157:H7 [5,16].

$\mathrm{O}$ uso de poucos nutrientes se torna mais preocupante quando se avaliam amostras como a EB10, que foi fortemente formadora de biofilme em meio sem glicose, e é proveniente de carcaça coletada após o chiller. Este é um dos pontos do abatedouro que apresenta grande dificuldade de higienização durante a produção da carne de frango, tornando a presença de uma $S$. Heidelberg produtora de biofilme nestes locais um risco para a saúde pública. Existe a possibilidade de contaminação cruzada nas plantas frigoríficas, além do fato de que este é um sorovar implicado em surtos de infecções de origem alimentar que já vem apresentando relatos de multirresistência a antimicrobianos [11,15,20].

A adesão bacteriana pode ser dividida em estágios primários e secundários. $\mathrm{O}$ primeiro estágio é reversível e é determinado por variáveis físico-químicas, como as interações hidrofóbicas, forças eletrostáticas, forças de van der Walls, temperatura e forças hidrodinâmicas, que vão determinar a adesão entre as duas superfícies, a célula bacteriana e a superfície de interesse. $\mathrm{Na}$ adesão secundária, ocorre uma mediação molecular entre adesinas específicas e superfície, em que o micro-organismo consolida sua adesão através da produção de um complexo exopolissacarídeo e/ou ligando receptores específicos presentes nas pilis com a superfície do material. No final deste estágio, a adesão é irreversível [3,19].

Componentes da superfície celular promovem (hidrofobinas) ou reduzem (hidrofilinas) as propriedades que podem coexistir na superfície bacteriana, podendo ocorrer alterações na estrutura da matriz de exopolissacarídeos durante a curva de crescimento $[1,14]$. Pôde-se observar que, nas amostras avaliadas, houve grande alteração do índice de hidrofobicidade em relação ao tempo de incubação, podendo relacionálo com as diferentes fases de desenvolvimento da superfície bacteriana, conforme a bibliografia $[1,14]$.

Entretanto, outros fatores podem alterar os resultados referentes à hidrofobicidade, como o hidrocarboneto utilizado. Neste sentido, diferentes microorganismos já foram testados frente ao xileno, octano e hexadecano, obtendo variações nos resultados quanto ao volume de hidrocarboneto e bactéria avaliada. Os hidrocarbonetos simulam a superfície de adesão, e cada um deles tem um sítio de ligação diferente, com melhores ou piores resultados para cada microorganismo. Na bibliografia encontrada, o uso do xileno tem sido aconselhado para Salmonella spp. [1,13].

A presença de amostras altamente hidrofóbicas e de média hidrofobicidade quando foi utilizado 24 horas de incubação, sendo que essas mesmas amostras apresentaram a capacidade de formação de biofilme, nos fazem supor que, quanto maior o tempo de contato com a superfície, maior a chance de aderência destes micro-organismos, provavelmente devido a modificações nas características da superfície bacteriana das $S$. Heidelberg avaliadas. Além disso, observa-se a importância de avaliar, nestas amostras, outros hidrocarbonetos e diferentes tempos de incubação, além de estudar a formação de biofilmes em superfícies que estão diretamente em contato com os alimentos nos abatedouros de frangos de corte.

\section{CONCLUSÕES}

Os dados obtidos por este trabalho denotam grande relevância por demonstrar que as Salmonella Heidelberg isoladas de amostras coletadas em abatedouros de frangos de corte possuem a capacidade de serem hidrofóbicas e de formarem biofilme na superfície testada, o que pode induzir a uma maior permanência desses micro-organismos no ambiente de processamento na indústria e, consequentemente, a uma maior chance de transmissão aos alimentos, com riscos ao consumidor.

\section{NOTAS INFORMATIVAS}

${ }^{1}$ Laboratórios Difco, Sparks, USA.

${ }^{2}$ Cral artigos para laboratório Ltda, Cotia, Brasil.

${ }^{3}$ Vetec química fina LTDA, Duque de Caxias, Brasil.

${ }^{4}$ Anthos Labtec Instruments, Salzburg, Austria 


\section{REFERÊNCIAS}

1 Chia T.W., Fegan N., McMeekin T.A. \& Dykes G.A. 2008. Salmonella Sofia differs from other poultry-associated Salmonella serovars with respect to cell surface hydrophobicity. Journal of Food Protection. 71: 2421-2428.

2 Christensen G.D., Simpson W.A. \& Bisno A.L. 1982. Adherence of slime-producing Staphylococcus epidermidis to smooth surfaces. Infection Immunology. 37: 318-326.

3 Costerton J.W., Cheng K.J. \& Geesey G.G. 1995. Bacterial biofilms in nature and disease. Annual Review of Microbiology. 49: 711-745.

4 Delazari I. 1998. Aspectos microbiológicos ligados à segurança e qualidade da carcaça de aves. In: Anais da $8^{a}$ Semana Acadêmica Veterinária (São Paulo, Brasil). pp.71-77.

5 Dewanti R. \& Wong A.C.L. 1995. Influence of culture conditions on biofilm formation by Escherichia coli O157:H7. International Journal of Food Microbiology. 26: 147-164.

6 Dickel E.L., Santos L.R., Rodrigues L.B., Valle S.F. \& Cecatti D. 2005. Ocorrência de Salmonella em abatedouros de aves com tecnologia totalmente automatizada (grande porte), semiautomatizada (médio porte) e semiautomatizada (pequeno porte). Higiene Alimentar. 19: 62-67.

7 Donlan R.M. \& Costerton J.M. 2002. Biofilms: Survival Mechanisms of Clinically Relevant Microorganisms. Clinical Microbiology Review. 15: 167-193.

8 Forsythe S.J. 2002. Microbiologia da Segurança Alimentar. Porto Alegre: Artmed, 410p.

9 Girardello R. 2007. Estudo da Formação de Biofilme por Cepas de Pseudomonas aeruginosa Isoladas de Pacientes com Infecção Urinária. 45f. Londrina, PR. Dissertação (Mestrado em Microbiologia)-Programa de Pós-graduação em Microbiologia, Universidade Estadual de Londrina.

10 Jay J.M. 2005. Microbiologia de Alimentos. 6.ed. Porto Alegre: Artmed, 711 p.

11 Patchanee P., Zewde B.M., Tadesse D.A., Hoet A. \& Gebreyes W.A. 2008. Characterization of multidrug-resistant Salmonella enterica serovar Heidelberg isolated from humans and animals. Foodborne Pathogens and Disease. 5: 839-851.

12 Pitts B., Hamilton M.A., Zelver N. \& Stewart P.S. 2003. A microtiter-plate screening method for biofilm disinfection and removal. Journal of Microbiological Methods. 54: 269-276.

13 Rosenberg M., Gutnick D. \& Rosenberg E. 1980. Adherence of bacteria to hydrocarbons: A simple method for measuring cell-surface hydrophobicity. FEMS Microbiology Letters. 9: 29-33.

14 Rosenberg M. \& Kjelleberg S. 1986. Hydrophobic interactions in bacterial adhesion. Advances in Microbial Ecology. 9: 353-393.

15 Smith K.E., Medus C., Meyer S.D., Boxrud D.J., Leano F., Hedberg C.W., Elfering K., Braymen C., Bender J.B. \& Danila R.N. 2008. Outbreaks of salmonellosis in Minnesota (1998 through 2006) associated with frozen, microwaveable, breaded, stuffed chicken products. Journal of Food Protection. 71: 2153-2160.

16 Stepanovic S., Irkovic I.C., Ranin L. \& Svabic-Vlahovic M. 2004. Biofilm formation by Salmonella spp. and Listeria monocytogenes on plastic surface. Letters in Applied Microbiology. 38: 428-432.

17 Stepanovic S., Vukovic D., Dakic I., Savic B. \& Vlahovic M.S.A. 2000. Modified microtiter-plate test for quantification of staphylococcal biofilm formation. Journal of Microbiological Methods. 40: 175-179.

18 Stepanovic S., Vukovic D., Hola V., Bonaventura G., Djukic S., Irkovic I.C. \& Ruzicka F. 2007. Quantification of biofilm in microtiter plates: overview of testing conditions and practical recommendations for assessment of biofilm production by staphylococci. APMIS-Acta Pathologica, Microbiologica et Immunologica Scandinavica. 71: 687-690.

19 Vesterlund S., Paltta J., Karp M. \& Ouwehand A.C. 2005. Measurement of bacterial adhesion in vitro evaluation of different methods. Journal of Microbiological Methods. 60: 225-233.

20 Vincent V., Scott H.M., Harvey R.B., Alali W.Q. \& Hume M.E. 2007. Novel surveillance of Salmonella enterica serotype Heidelberg epidemics in a closed community. Foodborne Pathogens and Disease. 4: 375-385. 